\title{
Determination of Organochlorine and Synthetic Pyrethroid Pesticide Residues in Water Samples Collected from Different Locations of Bangladesh
}

\author{
Mohammad Dalower Hossain Prodhan*, Md. Sultan Ahmed, Nirmal Kumar Dutta, \\ Debasish Sarker, Syed Nurul Alam
}

Pesticide Analytical Laboratory, Pesticide Research and Environmental Toxicology Section, Entomology Division, Bangladesh Agricultural Research Institute, Gazipur, Bangladesh

Email: *dalowerag@yahoo.com, *mdhprodhan@gmail.com

How to cite this paper: Prodhan, M.D.H., Ahmed, Md.S., Dutta, N.K., Sarker, D. and Alam, S.N. (2021) Determination of Organochlorine and Synthetic Pyrethroid Pesticide Residues in Water Samples Collected from Different Locations of Bangladesh. Journal of Biophysical Chemistry, 12, 11-21. https://doi.org/10.4236/jbpc.2021.122002

Received: April 3, 2021

Accepted: May 27, 2021

Published: May 30, 2021

Copyright $\odot 2021$ by author(s) and Scientific Research Publishing Inc. This work is licensed under the Creative Commons Attribution International License (CC BY 4.0).

http://creativecommons.org/licenses/by/4.0/ (c) (i) Open Access

\begin{abstract}
The present study was aimed to validate an analytical method for the quantification of 19 organochlorine and 2 synthetic pyrethroid pesticide residues in water samples using modified quick, easy, cheap, effective, rugged and safe (QuEChERS) extraction and Gas Chromatography coupled with Electron Capture Detector (ECD). The selected pesticide residues were determined by inhouse validated method. The analytical method was validated by evaluating the accuracy, precision, linearity, limit of detection (LOD) and limit of quantification (LOQ). The average recoveries of the selected pesticides ranged from $78 \%$ to $117 \%$ with RSDr $\leq 12 \%$ in two fortification levels of 0.02 and 0.1 $\mathrm{mg} / \mathrm{L}$. The linearity was $\geq 0.995$ for all of the selected pesticides. The LOD ranged from 0.003 to $0.006 \mathrm{mg} / \mathrm{L}$ and the LOQ was $0.02 \mathrm{mg} / \mathrm{L}$ for all the selected analytes. This method was applied satisfactorily for the residue analysis of 108 water samples collected from nine districts of Bangladesh. Among the analyzed samples, only 4 had cypermethrin residues $(0.026 \mathrm{mg} / \mathrm{L}, 0.034 \mathrm{mg} / \mathrm{L}$, $0.045 \mathrm{mg} / \mathrm{L}$ and $0.05 \mathrm{mg} / \mathrm{L}$ ). The level of detected cypermethrin residues were above the WHO recommended guide line values of water quality.
\end{abstract}

\section{Keywords}

Organochlorine Pesticides, Synthetic Pyrethroid Pesticides, Water Samples, Residue Analysis, Gas Chromatography

\section{Introduction}

Water is one of the most important substances on earth. All plants and animals 
must have water to survive. If there was no water, there would be no life on earth. However, waters are contaminated by pesticides through percolation and runoff from agricultural land and channels, and from urban city sewage sites, thus affecting the quality of various water sources. The organochlorine pesticide (OCP) residues are still detectable in water due to their long persistence in the environment. Several works have indicated the presence of OCPs residues in waters [1] [2] [3].

Up until now, in Bangladesh, the farmers mostly depend on toxic chemical pesticides to prevent the crop loss caused by insect pests infestation and to increase the production. There are many reasons behind this. Pesticide adulteration is one of the major reasons for the indiscriminate use of pesticides. Due to adulteration, the activity of pesticides is reduced and that is why, the farmers are applying pesticides too often for the management of insect-pests and diseases as well as to control the weeds. As a result of frequent application of pesticides, their residues are remaining of different agricultural commodities.

Till today, in Bangladesh several researchers have been detected pesticide residues in vegetables [4]-[16], fruits [17], betel leaf [18], sugarcane [19], dry fish [20] and fish [21] [22]. Therefore, it is inevitable that the pond water, fresh water as well as the ground water may be contaminated with the residues of such toxic chemical pesticides used in the above mentioned crops by the farmers of Bangladesh.

In the analysis of pesticide residues, effective extraction and clean-up methods are essential. Nowadays, the quick, easy, cheap, effective, rugged and safe (QuECHERS) method is widely used for extraction and cleanup of pesticide residues in a wide variety of matrices [23] [24] [25] [26]. This method is gaining popularity day by day compared to the other existing methods as it has a lot of advantages. The important ones are high recoveries of analytes with low organic solvent consumption and the low cost per sample. Gas Chromatography coupled with Electron Capture Detector (GC-ECD) is widely used for the quantification of organochlorine and synthetic pyrethroid pesticides as they are very sensitive for the above mentioned groups of pesticides. On the other hand, GC-ECD are cheaper and have lower maintenance costs, hence are more readily available in some countries than mass spectrometers [17]. Therefore, the QuECHERS extraction technique followed by Gas Chromatography is a valuable tool for the quantification of organochlorine and synthetic pyrethroid pesticide residues in water samples.

The organochlorine pesticides create several adverse effects on human heath, and their associated health risk are monitored by several researchers [27] [28]. Keeping this view the present study was initiated to develop and validate an analytical method for the quantification of 19 organochlorine pesticides (alpha BHC, delta $\mathrm{BHC}$, beta $\mathrm{BHC}$, gama $\mathrm{BHC}$, heptachlor, aldrin, heptachlor epoxide, gama chlordane, alpha chlordane, alpha endosulfan, 4,4 DDE, dieldrin, endrin, 4,4 DDD, beta endosulfan, 4,4 DDT, endrin aldehyde, endosulfan sulphate, methoxychlor, and endrin ketone) and 2 synthetic pyrethroid pesticides residues (cy- 
permethrin, fenvalerate) and to monitor the selected organochlorine and synthetic pyrethroid pesticide residues in water samples collected from Bogura, Cumilla, Dhaka, Gazipur, Jamalpur, Jashore, Mymensingh, Narsingdi and Rangpur district of Bangladesh.

\section{Materials and Methods}

\subsection{Chemicals \& Reagents}

Reference standards of 19 organochlorine pesicide Mix (alpha BHC, delta BHC, beta BHC, gama BHC, heptachlor, aldrin, heptachlor epoxide, gama chlordane, alpha chlordane, alpha endosulfan, 4,4 DDE, dieldrin, endrin, 4,4 DDD, beta endosulfan, 4,4 DDT, endrin aldehyde, endosulfan sulphate, methoxychlor, and endrin ketone) and 2 synthetic pyrethroid pesticide (cypermethrin, fenvalerate) were obtained from SIGMA-Aldrich, Germany through SF Scientific, Dhaka. Analytical grade acetonitrile $(\mathrm{MeCN})$, methanol, sodium chloride $(\mathrm{NaCl})$, anhydrous magnesium sulphate $\left(\mathrm{MgSO}_{4}\right)$ and Primary Secondary Amine (PSA) were obtained from SIGMA-Aldrich, Germany through SF Scientific, Dhaka.

\subsection{Preparation of Pesticide Standard Solution}

Mixed pesticide standard stock solutions (200 ug/mL) of alpha BHC, delta BHC, beta BHC, gama BHC, heptachlor, aldrin, heptachlor epoxide, gama chlordane, alpha chlordane, alpha endosulfan, 4,4 DDE, dieldrin, endrin, 4,4 DDD, beta endosulfan, 4,4 DDT, endrin aldehyde, endosulfan sulphate, methoxychlor, and endrin ketone were prepared in hexane:toluene (50:50) except for cypermethrin and fenvalerate. In case of cypermethrin and fenvalerate it was acetonitrile. An intermediate mixed standard solution of $10 \mathrm{ug} / \mathrm{mL}$ in acetonitrile was prepared from the mixed standard solution of $200 \mathrm{ug} / \mathrm{mL}$. Then working standard solutions of $0.1,0.2,0.5,1.0,2.0$, and $3.0 \mathrm{ug} / \mathrm{mL}$ in acetonitrile were prepared by transferring the appropriate amount from $10 \mathrm{ug} / \mathrm{mL}$ intermediate mixed standard solution into six separate $5-\mathrm{mL}$ volumetric flasks. The pesticide standard solutions were prepared in the normal room temperature, after the preparation of standard solutions, all the standard solutions were kept in a freezer at $-20^{\circ} \mathrm{C}$ until use.

\subsection{Sample Preparation}

The quick, easy, cheap, effective, rugged and safe (QuEChERS) extraction technique, which was first introduced by Anastassiades and their associates [29], is widely used for the extraction and cleanup of pesticide residues for a wide variety of matrices. The QuEChERS extraction method modified by Prodhan and their associates [30], was used for the extraction and clean-up of the selected pesticides from water samples. In brief, $10 \mathrm{~mL}$ of water sample was taken in a 50 $\mathrm{mL}$ screw-capped polypropylene centrifuge tube and $10 \mathrm{~mL}$ acetonitrile $(\mathrm{MeCN})$ was added into the centrifuge tube. The centrifuge tube was closed properly and shaken vigorously for $30 \mathrm{sec}$. by vortex mixer. Then $4 \mathrm{~g}$ anhydrous $\mathrm{MgSO}_{4}, 1 \mathrm{~g}$ 
$\mathrm{NaCl}$ were added into the centrifuge tube and it was shaken by vortex mixer for 1 minute. Afterwards, the extract was centrifuged for $5 \mathrm{~min}$ at $5000 \mathrm{rpm}$. An aliquot of $3 \mathrm{~mL}$ of the $\mathrm{MeCN}$ layer was transferred into a $15 \mathrm{~mL}$ micro centrifuge tube containing $600 \mathrm{mg}$ anhydrous $\mathrm{MgSO}_{4}$ and $120 \mathrm{mg}$ Primary Secondary Amine (PSA). The content of the centrifuge tube was thoroughly mixed by vortex for 30 sec. and centrifuged for 5 minutes at $4000 \mathrm{rpm}$. After centrifuge, a $1 \mathrm{~mL}$ supernatant was filtered by a $0.2 \mu \mathrm{m}$ PTFE filter, and then it was taken in a clean GC vial for injection.

\subsection{Operating Condition of GC}

The concentrations of the extracted organochlorine and synthetic pyrethroid pesticides was detected by GC-ECD (Shimadzu GC-2010), coupled with a capillary column of $30 \mathrm{~m}$ long $\times 0.32 \mathrm{~mm}$ ID $\times 0.25 \mu \mathrm{m}$ film thicknesses (Rtx-CLPesticides2). The GC-ECD was handled in split mode. Nitrogen was used as carrier (column flow rate $2.71 \mathrm{~mL} \cdot \mathrm{min}^{-1}$ ) and make up gas (flow rate- $15 \mathrm{~mL} \cdot \mathrm{min}^{-1}$ ).

In case of organochlorine pesticides, the injector and detector temperatures were set to $250^{\circ} \mathrm{C}$ and $330^{\circ} \mathrm{C}$, respectively and the column oven temperature was programmed, which was started from $180^{\circ} \mathrm{C}$ and went up to $220^{\circ} \mathrm{C}$ with an incremental rate of $5^{\circ} \mathrm{C}(12 \mathrm{~min}$ hold $)$, then it raised to $260^{\circ} \mathrm{C}$ with an incremental rate of $5^{\circ} \mathrm{C}$. All the injections $(1 \mu \mathrm{L})$ were done in spit mode. The total run time was $28 \mathrm{~min}$.

However, in case of cypermethrin, the injector and detector temperatures were set to $280^{\circ} \mathrm{C}$ and $300^{\circ} \mathrm{C}$, respectively, and the column oven temperature was programmed as follows: initial temperature of $160^{\circ} \mathrm{C}$ was held for $1 \mathrm{~min}$ and ramped to $270^{\circ} \mathrm{C}$ with an incremental rate of $10^{\circ} \mathrm{C}$ was held for $8 \mathrm{~min}$, resulting the total run time of $20 \mathrm{~min}$. While, in case of fenvalerate, the injector and detector temperatures were set to $280^{\circ} \mathrm{C}$ and $300^{\circ} \mathrm{C}$, respectively, and the column oven temperature was programmed as follows: initial temperature of $160^{\circ} \mathrm{C}$ and ramped to $230^{\circ} \mathrm{C}$ with an incremental rate of $10^{\circ} \mathrm{C}$, and finally went to $270^{\circ} \mathrm{C}$ with an incremental rate of $2^{\circ} \mathrm{C}$ resulting the total run time of $27 \mathrm{~min}$. Identification of the analyte in the extracted samples was done by comparing the retention time of the corresponding calibration standard and quantification was done by the external calibration curves maid with 6 point calibration standard.

\section{Results and Discussions}

\subsection{Method Validation}

The analytical method was validated by evaluating the accuracy, precision, limit of detection, limit of quantification and linearity.

\subsubsection{Accuracy and Precision}

The accuracy of the method was calculated as \% recovery of pesticides from spiked samples. Pesticide free $10 \mathrm{~mL}$ water sample was spiked prior to the determination procedure by the addition of a mixed pesticide standard working solution to reach the final fortification levels of 0.02 , and $0.10 \mathrm{mg} / \mathrm{L}$. For each 
level, five replicates were analyzed. After the addition of each concentration in the matrix, the mixture was equilibrated by shaking and the samples were allowed to settle for 30 minutes prior to extraction in order to ensure the sufficient contact of the analytes with the whole matrix. Then, the samples were prepared according to the method which was described earlier. Precision in case of repeatability $\left(\mathrm{RSD}_{\mathrm{r}}\right)$ was determined at two fortification levels of 0.02 , and $0.10 \mathrm{mg} / \mathrm{L}$ with 5 replicates on the same day. A very good accuracy and precision was found for all of the analytes. The average recoveries ranged from $78 \%$ to $117 \%$ with relative standard deviations $\left(\mathrm{RSD}_{\mathrm{r}}\right) \leq 12 \%$ for all of the analytes (Table 1 ).

\subsubsection{Limit of Detection (LOD) and Limit of Quantification (LOQ)}

The LOD was calculated according to EURACHEM guidelines [31]. In order to determine the LOD of each analyte 10 independent sample blanks fortified at the lowest acceptable concentration of $0.02 \mathrm{mg} / \mathrm{L}$ were injected and the LOD was expressed as the analyte concentration corresponding to 3 times the standard

Table 1. Mean recovery (\%) and RSD (\%) of the selected pesticides in water samples.

\begin{tabular}{|c|c|c|c|c|}
\hline \multirow{3}{*}{ Pesticides } & \multicolumn{4}{|c|}{ Fortification level } \\
\hline & \multicolumn{2}{|c|}{$0.02 \mathrm{mg} / \mathrm{L}$} & \multicolumn{2}{|c|}{$0.1 \mathrm{mg} / \mathrm{L}$} \\
\hline & Mean (\%) & RSD (\%) & Mean (\%) & RSD (\%) \\
\hline Alpha BHC & 82 & 4 & 87 & 6 \\
\hline Delta BHC & 85 & 7 & 81 & 9 \\
\hline Beta BHC & 84 & 3 & 93 & 4 \\
\hline Gama BHC & 117 & 5 & 116 & 7 \\
\hline Heptachlor & 86 & 8 & 88 & 5 \\
\hline Aldrin & 78 & 7 & 79 & 5 \\
\hline Heptachlor Epoxide & 82 & 5 & 82 & 5 \\
\hline Gama Chlordane & 80 & 6 & 87 & 9 \\
\hline Alpha Chlordane & 81 & 3 & 89 & 8 \\
\hline Alpha Endosulfan & 82 & 9 & 102 & 8 \\
\hline 4,4 DDE & 83 & 8 & 84 & 6 \\
\hline Dieldrin & 84 & 11 & 89 & 9 \\
\hline Endrin & 86 & 7 & 89 & 12 \\
\hline 4,4 DDD & 88 & 9 & 90 & 9 \\
\hline Beta Endosulfan & 86 & 6 & 93 & 7 \\
\hline 4,4 DDT & 86 & 5 & 87 & 4 \\
\hline Endosulfan sulphate & 113 & 4 & 110 & 8 \\
\hline Methoxychlor & 86 & 8 & 88 & 7 \\
\hline Endrin ketone & 85 & 10 & 81 & 6 \\
\hline Cypermethrin & 97 & 6 & 105 & 6 \\
\hline Fenvalerate & 102 & 5 & 94 & 8 \\
\hline
\end{tabular}


deviation. The LOQ was determined according to the European Commission (EC) document no. SANTE/12682/2019 [32]. The LOQ was set at the lowest fortification level for each pesticides that was achieved the acceptable accuracy (mean recoveries for individual pesticides in the range of $70 \%-120 \%$ ) and precision (RSDr $\leq 20 \%)$.

The LOD of each analyte is presented in Table 2. The LOD ranged from 0.003 to $0.006 \mathrm{mg} / \mathrm{L}$. The LOQ for all of the selected pesticides was set to $0.02 \mathrm{mg} / \mathrm{L}$ which was achieved the acceptable accuracy (mean recoveries for individual pesticides in the range of $78 \%$ to $117 \%$ ) and precision (RSDr $\leq 11 \%$ ).

\subsubsection{Calibration Curve \& Linearity}

Six point calibration curves were prepared by working standard solutions of $0.01,0.02,0.05,0.10,0.20$, and $0.30 \mathrm{ug} / \mathrm{mL}$ in acetonitrile and analyzed in triplicate. Calibration curves were made by plotting the mean peak area of the selected pesticides versus concentration. Linearity was very good and coefficients of determination were $\geq 0.995$ for all of the selected pesticides. The correlation

Table 2. Retention time (RT), limit of detection (LOD), limit of quantification (LOQ) and coefficient of determination $\left(\mathrm{R}^{2}\right)$ of the selected pesticides in water.

\begin{tabular}{|c|c|c|c|c|c|}
\hline \multicolumn{2}{|c|}{ Pesticides } & \multirow{2}{*}{$\begin{array}{l}\text { RT } \\
5.48\end{array}$} & \multicolumn{2}{|c|}{ LOD $(\mathrm{mg} / \mathrm{L})$ LOQ $(\mathrm{mg} / \mathrm{L})$} & \multirow{2}{*}{$\begin{array}{c}\mathbf{R}^{2} \\
0.995\end{array}$} \\
\hline & Alpha BHC & & 0.003 & & \\
\hline & Delta BHC & 6.33 & 0.003 & & 0.997 \\
\hline & Beta BHC & 6.55 & 0.005 & & 0.995 \\
\hline & Gama BHC & 7.33 & 0.004 & & 0.996 \\
\hline & Heptachlor & 7.46 & 0.005 & & 0.998 \\
\hline & Aldrin & 8.36 & 0.004 & & 0.997 \\
\hline & Heptachlor Epoxide & 10.31 & 0.005 & & 0.998 \\
\hline & Gama Chlordane & 11.07 & 0.004 & & 0.999 \\
\hline & Alpha Chlordane & 11.73 & 0.005 & & 0.996 \\
\hline \multirow[t]{10}{*}{ Organochlorine } & Alpha Endosulfan & 11.97 & 0.005 & 0.02 & 0.998 \\
\hline & 4,4 DDE & 12.67 & 0.004 & & 0.996 \\
\hline & Dieldrin & 13.37 & 0.005 & & 0.996 \\
\hline & Endrin & 15.15 & 0.006 & & 0.997 \\
\hline & 4,4 DDD & 16.33 & 0.006 & & 0.997 \\
\hline & Beta Endosulfan & 16.69 & 0.005 & & 0.998 \\
\hline & 4,4 DDT & 18.83 & 0.006 & & 0.996 \\
\hline & Endosulfan sulphate & 22.05 & 0.006 & & 0.998 \\
\hline & Methoxychlor & 24.96 & 0.005 & & 0.995 \\
\hline & Endrin ketone & 25.67 & 0.006 & & 0.997 \\
\hline \multirow{2}{*}{ Synthetic Pyrethroid } & Cypermethrin & 12.81 & 0.005 & \multirow{2}{*}{0.02} & 0.996 \\
\hline & Fenvalerate & 24.46 & 0.006 & & 0.997 \\
\hline
\end{tabular}


coefficients for all of the selected pesticides are summarized in Table 2.

\subsection{Application of the Method for Real Sample Analysis}

The concentrated extracts of water samples collected from different locations (Bogura, Cumilla, Dhaka, Gazipur, Jamalpur, Jashore, Mymensingh, Narsingdi and Rangpur) were analyzed by GC-2010 (Shimadzu) with Electron Capture Detector (ECD) with the pre-set parameters. The level of detected pesticide residues found in the analyzed samples is outlined in Table 3. A total of 108 samples were collected from 9 different districts of Bangladesh and were analyzed. Out of 108 analyzed samples, only 4 (3.7\% of the analyzed samples) had cypermethrin residues. The level of cypermethrin residues were $0.026 \mathrm{mg} / \mathrm{L}, 0.034$ $\mathrm{mg} / \mathrm{L}, 0.045 \mathrm{mg} / \mathrm{L}$ and $0.05 \mathrm{mg} / \mathrm{L}$, respectively. The level of detected cypermethrin residues were above the WHO recommended guide line values of water quality. The results of the present study are in a good agreement with the findings of Uddin and their associates [33]. They have also found that cypermethrin was the most frequently found pesticide in the analyzed water samples. It is a good indication for the peoples of Bangladesh that none of the analyzed samples were found contaminated with toxic organochlorine pesticides. On the other hand, only $3.7 \%$ analyzed samples were found contaminated with the residues of cypermethrin.

The water samples collected from Bogura, Cumilla, Dhaka, Jamalpur, Jashore, Narsingdi and Rangpur did not contained any residues of the 21 analyzed pesticides. The four contaminated samples were collected from Gazipur and Mymensingh. Among these 4 contaminated samples, 3 were collected from Mymensingh and 1 was from Gazipur. The samples collected from Bogura, Cumilla, Dhaka, Jamalpur, Jashore, Narsingdi and Rangpur did not contained any residues might

Table 3. Residue levels (mg/L) found in water samples collected from different locations of Bangladesh.

\begin{tabular}{|c|c|c|c|c|c|}
\hline $\begin{array}{c}\text { Area of } \\
\text { collection }\end{array}$ & $\begin{array}{c}\text { Analyzed } \\
\text { samples (No.) }\end{array}$ & $\begin{array}{l}\text { Contaminated } \\
\text { samples (No.) }\end{array}$ & $\begin{array}{l}\text { Detected } \\
\text { pesticides }\end{array}$ & $\begin{array}{c}\text { Residue levels } \\
\text { (mg/L) }\end{array}$ & $\begin{array}{c}\text { WHO recommended } \\
\text { value }(\mathrm{mg} / \mathrm{L})\end{array}$ \\
\hline Bogura & 12 & - & $\mathrm{ND}^{*}$ & - & - \\
\hline Cumilla & 12 & - & $\mathrm{ND}^{*}$ & - & - \\
\hline Dhaka & 12 & - & $\mathrm{ND}^{*}$ & - & - \\
\hline Gazipur & 12 & 1 & Cypermethrin & 0.05 & 0.02 \\
\hline Jamalpur & 12 & - & $\mathrm{ND}^{*}$ & - & - \\
\hline Jashore & 12 & - & $\mathrm{ND}^{*}$ & - & - \\
\hline Mymensingh & 12 & 3 & Cypermethrin & $0.026-0.045$ & 0.02 \\
\hline Narsingdi & 12 & - & $\mathrm{ND}^{*}$ & - & - \\
\hline Rangpur & 12 & - & $\mathrm{ND}^{*}$ & - & - \\
\hline Total & 108 & 4 & & & \\
\hline
\end{tabular}

ND*-Not Detected. 
be the reason of sample type as from these locations, only the drinking water was collected. However, in case of Mymensingh and Gazipur along with the drinking water, pond water samples were also collected, and from these both locations, the contaminated samples were originated from the pond water samples. Therefore, it is necessary to collect and analyze the pond water samples from different locations of the country as the farmers of Bangladesh are using different pesticides for the production of rice and vegetables. Hence, the residues of pesticides may remain in pond water adjacent to the rice and vegetable field. In our future study, emphasis should be given to analyze pond and river water as well as fresh water samples in order to find out the actual scenario of water contamination by different pesticides.

\section{Conclusion}

The proposed method in this study is an efficient, easy and effective multi-residue analytical method for the analysis of 19 organochlorine and 2 synthetic pyrethroid pesticide residues in water samples using Gas Chromatography coupled to Electron Capture Detector (GC-ECD). In this study, a very good accuracy and precision was found for all the analytes. The average recoveries ranged from $78 \%$ to $117 \%$ with $\mathrm{RSD}_{\mathrm{r}} \leq 12 \%$ in two fortification levels of 0.02 and $0.1 \mathrm{mg} / \mathrm{L}$. The linearity was $\geq 0.995$ for all of the selected pesticides. The LOD ranged from 0.003 to $0.006 \mathrm{mg} / \mathrm{L}$ and the LOQ was $0.02 \mathrm{mg} / \mathrm{L}$. Moreover, a total of 108 water samples collected from nine districts of Bangladesh were analyzed successfully using this proposed analytical method. Among the analyzed samples, only 4 had cypermethrin residues $(0.026 \mathrm{mg} / \mathrm{L}, 0.034 \mathrm{mg} / \mathrm{L}, 0.045 \mathrm{mg} / \mathrm{L}$ and $0.05 \mathrm{mg} / \mathrm{L})$. The level of detected cypermethrin residues were above the WHO recommended guide line values of water quality [34]. Thus, the proposed method can be used successfully to monitor organochlorine and synthetic pyrethroid pesticide residues in water samples.

\section{Acknowledgements}

The authors are grateful to Md. Kamal Hossain in the Pesticide Analytical Laboratory, Pesticide Research \& Environmental Toxicology Section, Entomology Division of BARI for his sincere cooperation during the present study.

\section{Conflicts of Interest}

The authors declare no conflicts of interest regarding the publication of this paper.

\section{References}

[1] Dem, S.B., Cobb, J.M. and Mullins, D.E. (2007) Pesticide Residues in Soil and Water from Four Cotton Growing Areas of Mali, West Africa. Journal of Agricultural Food and Environmental Sciences, 1, 1-12.

[2] Imo, S.T., Sheikh, M.A., Hirosawa, E., Oomori, E.T. and Tamaki, F. (2007) Contamination by Organochlorine Pesticides from Rivers. International Journal of En- 
vironmental Science and Technology, 4, 1-9. https://doi.org/10.1007/BF03325955

[3] Ize-Iyamu, O.K., Asia, I.O. and Egwakhide, P.A. (2007) Concentrations of Residues from Organochlorine Pesticide in Water and Fish from Some Rivers in Edo State Nigeria. International Journal of Physical Science, 2, 237-241.

[4] Habib, M., Kaium, A., Khan, M.S.I., Prodhan, M.D.H., Begum, N., Chowdhury, M.T.I. and Islam, M.A. (2021) Residue Level and Health Risk Assessment of Organophosphorus Pesticides in Eggplant and Cauliflower Collected from Dhaka City, Bangladesh. Food Research, 5, 369-377. https://doi.org/10.26656/fr.2017.5(3).624

[5] Nahar, K.M., Khan, M.S.I., Habib, M., Hossain, S.M., Prodhan, M.D.H. and Islam, M.A. (2020) Health Risk Assessment of Pesticide Residues in Vegetables Collected from Northern Part of Bangladesh. Food Research, 4, 2281-2288.

https://doi.org/10.26656/fr.2017.4(6).309

[6] Islam, M.A., Ullah, A., Habib, M., Chowdhury, M.T.I., Khan, M.S.I., Kaium, A. and Prodhan, M.D.H. (2019) Determination of Major Organophosphate Insecticide Residues in Cabbage Samples from Different Markets of Dhaka. Asia Pacific Environmental and Occupational Health Journal, 5, 30-35.

[7] Islam, M.S., Prodhan, M.D.H. and Uddin, M.K. (2019) Determination of Major Organophosphorus Pesticide Residues in Eggplant Using QuEChERS Extraction and Gas Chromatography. International Journal of Innovative Science and Research Technology, 4, 212-219.

[8] Islam, M.S., Prodhan, M.D.H. and Uddin, M.K. (2019) Analysis of the Pesticide Residues in Bitter Gourd Using Midified QuEChERS Extraction Coupled with Gas Chromatography. Asia Pacific Environmental and Occupational Health Journal, 5, 6-15.

[9] Prodhan, M.D.H., Akon, M.W. and Alam, S.N. (2018) Determination of Pre-Harvest Interval for Quinalphos, Malathion, Diazinon and Cypermethrin in Major Vegetables. Journal of Environmental and Analytical Toxicology, 8, 553.

[10] Prodhan, M.D.H. and Alam, S.N. (2018) Determination of Multiple Organochlorine Pesticide Residues in Shrimp Using Modified QuEChERS Extraction and Gas Chromatography. SAARC Journal of Agriculture, 16, 81-93.

https://doi.org/10.3329/sja.v16i1.37425

[11] Prodhan, M.D.H., Akon, M.W. and Alam, S.N. (2018) Decontamination of Organophosphorus Insecticide Residues from Eggplant and Yard Long Bean. International Journal of Experimental Agriculture, 8, 6-9.

[12] Hasan, R., Prodhan, M.D.H., Rahman, S.M.M., Khanom, R. and Ullah, A. (2017) Determination of Organophosphorus Insecticide Residues in Country Bean Collected from Different Markets of Dhaka. Journal of Environmental and Analytical Toxicology, 7, 489. https://doi.org/10.4172/2161-0525.1000489

[13] Aktar, M.A., Khatun, R. and Prodhan M.D.H. (2017) Determination of Pesticide Residues in Eggplant Using Modified QuEChERS Extraction and Gas Chromatography. International Journal of Agronomy and Agricultural Research, 11, 22-31.

[14] Islam, M.W., Dastogeer, K.M.G., Hamim, I., Prodhan, M.D.H. and Ashrafuzzaman, M. (2014) Detection and Quantification of Pesticide Residues in Selected Vegetables of Bangladesh. Journal of Phytopathology and Pest Management, 1, 17-30.

[15] Hossain, M.S., Rahman, M.M., Kabir, K.H., Miah, M.R.U. and Prodhan, M.D.H. (2014) Determination of Pre-Harvest Interval (PHI) for Cypermethrin and Acephate in Yard-Long Bean under Supervised Field Trail. Bangladesh Journal of Entomology, 24, 101-115.

[16] Kabir, K.H., Rahman, M.A., Ahmed, M.S., Prodhan, M.D.H. and Akon, M.W. (2008) 
Determination of Residue of Diazinon and Carbosulfan in Brinjal and Quinalphos in Yard Long Bean under Supervised Field Trial. Bangladesh Journal of Agricultural Research, 33, 503-513. https://doi.org/10.3329/bjar.v33i3.1609

[17] Prodhan, M.D.H., Afroze, M., Begum, A. and Sarker, D. (2021) Determination of Organophosphorus and Synthetic Pyrethroid Pesticide Residues and Their Variability in Large Size Fruit Crops. Journal of the Science of Food and Agriculture, 101, 4847-4854. https://doi.org/10.1002/jsfa.11131

[18] Prodhan, M.D.H., Afroze, M., Begum, A., Ahmed, M.S. and Sarker, D. (2021) Optimization of a QuEChERS Based Analytical Method for the Determination of Organophosphorus and Synthetic Pyrethroid Pesticide Residues in Betel Leaf. International Journal of Environmental Analytical Chemistry. https://doi.org/10.1080/03067319.2021.1873311

[19] Kabir, K.H., Abdullah, M., Prodhan, M.D.H., Ahmed, M.S. and Alam, M.N. (2007) Determination of Carbofuran Residue in the Samples of Sugarcane and Soil of Sugarcane Field. The Agriculturist, 5, 61-66. https://doi.org/10.3329/agric.v5i1.5199

[20] Rahman, M.R., Islam, M.S., Rahman, M.M., Prodhan, M.D.H. and Uddin, M.K. (2019) Organochlorine Pesticide Residue Status in Dry Fish of Bangladesh and Their Risk Assessment: A Review. International Journal of Scientific and Research Publications, 9, 619-639. https://doi.org/10.29322/IJSRP.9.10.2019.p9480

[21] Prodhan, M.D.H., Rahman, M.A., Ahmed, M.S. and Kabir, K.H. (2010) Pesticides Residues in Fish Samples Collected from Different Fish Cultivation Regions of Bangladesh. SAARC Journal of Agriculture, 8, 53-64.

[22] Prodhan, M.D.H., Rahman, M.A., Ahmed, M.S. and Kabir, K.H. (2009) Quantification of Organophosphorous and Organochlorine Insecticide from Fish Samples Using Simple GC Technique. Bangladesh Journal of Agriculturist, 2, 197-204.

[23] Prodhan, M.D.H., Papadakis, E.N. and Papadopoulou-Mourkidou, E. (2018) Variability of Pesticide Residues in Eggplant Units Collected from a Field Trial and Marketplaces in Greece. Journal of the Science of Food and Agriculture, 98, 2277-2284. https://doi.org/10.1002/jsfa.8716

[24] Prodhan, M.D.H., Papadakis, E.N. and Papadopoulou-Mourkidou, E. (2016) Analysis of Pesticide Residues and Their Variability in Cabbage Using QuEChERS Extraction in Combination with LC-MS/MS. Food Analytical Methods, 9, 3470-3478. https://doi.org/10.1007/s12161-016-0537-Z

[25] Prodhan, M.D.H., Papadakis, E.N. and Papadopoulou-Mourkidou, E. (2016) Variability of Pesticide Residues in Cauliflower Units Collected from a Field Trial, and Market Places in Greece. Journal of Environmental Science and Health, Part B, 51, 644-653. https://doi.org/10.1080/03601234.2016.1181922

[26] Prodhan, M.D.H., Papadakis, E.N. and Papadopoulou-Mourkidou, E. (2015) Analysis of Pesticide Residues in Melon Using QuEChERS Extraction and Liquid Chromatography Triple Quadrupole Mass Spectrometry. International Journal of Environmental Analytical Chemistry, 95, 1219-1229. https://doi.org/10.1080/03067319.2015.1025227

[27] Khwaja, S., Mushtaq, R., Mushtaq, R., Yousuf, M., Attaullah, M., Tabbassum, F. and Faiz, R. (2013). Monitoring of Biochemical Effects of Organochlorine Pesticides on Human Health. Health, 5, 1342-1350. https://doi.org/10.4236/health.2013.58182

[28] Adefemi, S., Asaolu, S., Ibigbami, O., Orege, J., Azeez, M. and Akinsola, (2018) Multi-Residue Levels of Persistent Organochlorine Pesticides in Edible Vegetables: A Human Health Risk Assessment. Journal of Agricultural Chemistry and Environment, 7, 143-152. https://doi.org/10.4236/jacen.2018.74013 
[29] Anastassiades, M., Lehotay, S.J., Stajnbaher, D. and Schenck, F.J. (2003) Fast and Easy Multiresidue Method Employing Acetonitrile Extraction/Partitioning and "Dispersive Solid-Phase Extraction" for the Determination of Pesticide Residues in Produce. Journal of AOAC International, 86, 412-431.

https://doi.org/10.1093/jaoac/86.2.412

[30] Prodhan, M.D.H., Papadakis, E.N. and Papadopoulou-Mourkidou, E. (2015) Determination of Multiple Pesticide Residues in Eggplant with Liquid Chromatography-Mass Spectrometry. Food Analytical Methods, 8, 229-235.

https://doi.org/10.1007/s12161-014-9898-3

[31] EURACHEM (2014) The Fitness for Purpose of Analytical Methods. https://www.eurachem.org/images/stories/Guides/pdf/MV guide 2nd ed EN.pdf

[32] European Commission (2019) Analytical Quality Control and Method Validation Procedures for Pesticide Residues Analysis in Food \& Feed. Document No. SANTE/ $12682 / 2019$.

[33] Uddin, M.A., Auwal, M.A., Chowdhuy, M.A.Z., Rahman, M.A. and Alam, M.K. (2012) Pesticide Residues in Some Selected Pond Waters of Bangladesh. Bangladesh Journal of Scientific Research, 25, 93-985. https://doi.org/10.3329/bjsr.v25i1.13054

[34] WHO (1996) Guidelines for Drinking Water Quality. 2nd Edition, Vol. 2, Health Criteria and Other Supporting Information, 940-949. 